\title{
A influência da vitamina D sobre o câncer: uma revisão integrativa
}

\author{
The influence of vitamin D on cancer: an integrative review \\ La influencia de la vitamina $D$ en el cáncer: una revisión integradora
}

Recebido: 21/12/2020 | Revisado: 27/12/2020 | Aceito: 30/12/2020 | Publicado: 04/01/2021

\author{
Mauro Celso de Souza \\ ORCID: https://orcid.org/0000-0003-4988-2879 \\ Universidade do Oeste de Santa Catarina, Brasil \\ E-mail: mauroosouzaa@hotmail.com \\ Marceli Pitt Coser \\ ORCID: https://orcid.org/0000- 0003-0430-6392 \\ Universidade do Oeste de Santa Catarina, Brasil \\ E-mail: marceli.coser@unoesc.edu.br
}

\begin{abstract}
Resumo
Marco teórico: o câncer é um conjunto de mais de cem doenças, das quais possuem fatores intrínsecos e/ou extrínsecos, modificáveis e não modicáveis para o seu desencadeamento. A vitamina $\mathrm{D}$, por sua vez, é um hormônio esteroide que possui as suas ações biológicas mediadas pelo receptor de vitamina $\mathrm{D}$, desenvolvendo, consequentemente, papéis relacionados ao controle do crescimento, diferenciação e proliferação celular, em que, a administração dos seus metabólicos ativos ou análogos podem resultar na inibição da angiogênese, delegando efeitos antiproliferativos e ativação dos mecanismos apoptóticos. Objetivo: esclarecer a influência da ação da vitamina D sobre os cânceres que acometem o trato gastrointestinal e órgãos distintos. Metodologia: trata-se de uma revisão integrativa, com abordagem qualitativa. A partir de buscas nas bases de dados BVS e PubMed, foram selecionados 19 artigos congruentes à temática e aos critérios de inclusão e exclusão, através da associação de descritores e palavraschaves. Resultados: $84,62 \%$ e $71,43 \%$ dos estudos expuseram uma correlação positiva da vitamina D no processo anti-carcinogênese dos cânceres que acometem o trato gastrointestinal e órgãos distintos, respectivamente. O processo de carcinogênese pode ser influenciado pela deficiência de vitamina $\mathrm{D}$, polimorfismos no gene receptor da vitamina $\mathrm{D}$ e demais alterações e relações com vias subjacentes. Conclusão: Destaca-se neste estudo a influência positiva da vitamina D na prevenção da carcinogênese que acomete o trato gastrointestinal e órgãos distintos.
\end{abstract}

Palavras-chave: Oncologia; Neoplasia; Calcitriol; Prevenção de doenças.

\begin{abstract}
Theoretical framework: cancer is a group of more than one hundred diseases, of which have intrinsic and/or extrinsic factors, modifiable and non-modifiable for its onset. Vitamin D, in turn, is a steroid hormone that has its biological actions mediated by the vitamin D receptor, consequently developing roles related to the control of cell growth, differentiation and proliferation, in which, the administration of its active metabolites or analogues can result in inhibition of angiogenesis, delegating effects antiproliferative and activation of apoptotic mechanisms. Objective: Present the influence of vitamin D action on cancers that affect the gastrointestinal tract and distinct organs. Methodology: It is an integrative review, with a qualitative approach. Based on research on BVS and PubMed databases, 19 articles were selected that were consistent with the theme and the inclusion and exclusion criteria, through the association of descriptors and keywords. Results: $84.62 \%$ and $71.43 \%$ of the studies demonstrated a positive correlation of vitamin $\mathrm{D}$ in the anti-carcinogenesis process of cancers that affect the gastrointestinal tract and different organs, respectively. The carcinogenesis process can be influenced by vitamin D deficiency, polymorphisms in the vitamin D receptor gene and other changes and relationships with underlying pathways. Conclusion: This study highlights the positive influence of vitamin D in the prevention of carcinogenesis that affects the gastrointestinal tract and different organs.
\end{abstract}

Keywords: Oncology; Neoplasm; Calcitriol; Prevention of diseases.

\section{Resumen}

Marco teórico: el cáncer es un grupo de más de cien enfermedades, de las cuales tienen factores intrínsecos y/o extrínsecos, modificables y no modificables para su aparición. La vitamina $\mathrm{D}$, a su vez, es una hormona esteroidea que tiene sus acciones biológicas mediadas por el receptor de vitamina $\mathrm{D}$, por lo que desarrolla roles relacionados con el control del crecimiento, diferenciación y proliferación celular, en los cuales, la administración de sus metabolitos activos. o análogos pueden resultar en la inhibición de la angiogénesis, permitido efectos antiproliferativos y activación de mecanismos apoptóticos. Objetivo: esclarecer la influencia de la acción de la vitamina D sobre los cánceres que afectan al tracto gastrointestinal y diferentes órganos. Metodología: esta es una revisión integradora, con 
enfoque cualitativo. Mediante búsquedas en las bases de datos de BVS y PubMed, 19 artículos fueran seleccionados consistentes con el tema y los criterios de inclusión y exclusión, a través de la asociación de descriptores y palabras clave. Resultados: El 84,62\% y el 71,43\% de los estudios expusieron una correlación positiva de la vitamina D en el proceso anticancerígeno de cánceres que afectan el tracto gastrointestinal y diferentes órganos, respectivamente. El proceso de carcinogénesis puede verse influenciado por la deficiencia de vitamina $\mathrm{D}$, los polimorfismos en el gen del receptor de vitamina D y otros cambios y relaciones con las vías subyacentes. Conclusión: En este estudio se destaca la influencia positiva de la vitamina $\mathrm{D}$ en la prevención de la carcinogénesis que afecta el tracto gastrointestinal y diferentes órganos.

Palabras clave: Oncología; Neoplasma; Calcitriol; Prevención de enfermedades.

\section{Introdução}

O câncer (CA) é um conjunto de mais de cem doenças, das quais possuem como característica principal o crescimento celular desordenado, ocorrendo a perda do controle de divisão das células, podendo invadir tecidos e órgãos vizinhos. As neoplasias podem ser classificadas como benignas e malignas (Brasil, 2020). É uma das quatro principais causas de morte prematura na maioria dos países, sendo o principal problema de saúde pública do mundo. Nos países em desenvolvimento, observa-se uma transição entre os principais tipos de CA, havendo um declínio nos tipos infecciosos e aumento daqueles associados às condições socioeconômicas e urbanização, como alimentação inadequada, sedentarismo e outros fatores (Bray et al., 2018).

$\mathrm{Na}$ epidemiologia, para o desenvolvimento de um tumor, há a necessidade da somatização de dois fatores, a causa necessária por um agente causador específico, e as predisponentes (outras forças). O processo de oncogênese/carcinogênese inicia a partir do dano a um ou a um grupo de genes de uma célula, que evolui quando há falhas nos mecanismos do sistema imunológico de destruição ou restauração celular. Entre 80\% e 90\% dos casos de CA estão relacionados a fatores extrínsecos e $20 \%$ a intrínsecos. Esses fatores podem interagir entre si, aumentando as chances de alterações malignas nas células normais. O desenvolvimento do CA depende da duração e intensidade da exposição celular aos agentes causadores (Brasil, 2020).

Associados aos fatores de risco para o desenvolvimento do CA, há a existência de condições não modificáveis, como etnia ou raça, gênero, hereditariedade e idade. E modificáveis, como exposição ao tabaco, bebidas alcoólicas, alimentos contaminados, agentes infecciosos, ocupacional, radiação ultravioleta e ionizante, poluição ambiental, situação econômica, inatividade física, sobrepeso, obesidade, e hábitos alimentares inadequados (Brasil, 2020). Dentre os fatores modificáveis, se discute o papel da vitamina D (Vit. D), já que dados epidemiológicos e pré-clínicos em humanos destacam que a sua deficiência está associada a causalidade de mortes por doenças cardiovasculares e CA (Schöttker et al., 2014).

A Vit. D é um hormônio esteroide que pode ser fotossintetizado na pele através da exposição à luz solar (radiação ultravioleta de alta energia) que penetra na pele (epiderme) e fotolisa o 7-desidrocolesterol, transformando-o em pré-vitamina D3 (Tian et al., 1993). Pode ser obtida a partir da alimentação ou suplementos dietéticos (Holick, 2007). Existem dois tipos, a vitamina D2 (ergocalciferol) e a vitamina D3 (colecalciferol) (Wacker \& Holick, 2013). A Vit. D é hidroxilada à 25hidroxicolecalciferol [25(OH)D3] no fígado e hidrolisada em calcitriol [1,25(OH)2D3] nos rins, sendo a forma ativa do hormônio (Deeb, Trump, \& Johnson, 2007).

As ações biológicas da forma ativa 1,25(OH)2D3 são mediadas pelo receptor de hormônios esteroides, o receptor de vitamina D (RVD) (Margolis \& Christakos, 2010). Os mecanismos genômicos da ação de 1,25(OH)2D3 envolve a ligação direta de 1,25(OH)2D3 RVD/Receptor Retinóide X (RXR) ativado a sequências específicas de DNA (elementos de resposta da Vit. D) e genes alvos, resultando na ativação ou repressão da transcrição (Christakos et al., 2015). Os genes RVD em camundongos e humanos estão localizados nos cromossomos 15 e 12, respectivamente (Zella et al., 2006).

Hodiernamente, no CA, a Vit. D merece destaque, pois o RVD desempenha funções homeostáticas fetais e adultas no 
desenvolvimento e diferenciação do sistema epidérmico, endócrino, imunológico, metabólico e neurológico. Por conseguinte, a Vit. D desenvolve papéis relacionados com o controle do crescimento, diferenciação e proliferação celular, e a administração dos seus metabólitos ativos ou de seus análogos inibem a angiogênese, possuem efeitos antiproliferativos e acabam ativando os mecanismos apoptóticos (El-Sharkawy \& Malki, 2020).

É necessário ter uma compreensão ampla, completa e detalhada que elucide a influência da Vit. D sobre a oncogênese, incluindo o esclarecimento dos mecanismos biológicos específicos dos órgãos, análises sorológicas, variações genéticas, biomarcadores clínicos, metabólicos e perfil metabolônico a partir da suplementação controlada com multidoses (Albanes, 2015).

Diante do exposto, o presente artigo busca realizar uma revisão integrativa de literatura para esclarecer a ação da Vit. D sobre os cânceres que acometem o trato gastrointestinal e os órgãos distintos.

\section{Metodologia}

Trata-se, pois, de uma revisão integrativa de literatura, que segundo Souza, Silva e Carvalho (2010, p. 105) "sintetiza as pesquisas disponíveis sobre determinada temática e direciona a prática fundamentando-se em conhecimento científico", através do método qualitativo, que para Pereira et al. (2018, p. 67) "são aqueles nos quais é importante a interpretação por parte do pesquisador com suas opiniões sobre o fenômeno em estudo".

Para a pesquisa, foram realizadas buscas em ordem alfabética nas seguintes bases de dados: Biblioteca Virtual em Saúde (BVS) - BIREME e Publicações Médicas (PubMed) - via National Library of Medicine, utilizando os seguintes descritores em inglês: "Vitamin D", "Calcitriol", "Carcinogenesis" e "Neoplasms". Todos os descritores utilizados para a pesquisa foram elegidos de acordo com os Descritores em Ciências da Saúde (DeCS), edição 2020. E, para amplificar e compor a pesquisa, foram elegidas as palavras-chaves "Oncogenesis" e "Cancer", que são sinônimos, respectivamente, dos descritores "Carcinogenesis" e "Neoplasms".

Com o objetivo de otimizar a qualidade da pesquisa, critérios de inclusão foram determinados, onde fizeram parte deste estudo apenas pesquisas empíricas (experimentais ou observacionais); artigos completos publicados entre agosto de 2015 e agosto de 2020 nos idiomas espanhol, inglês ou português; pesquisas que utilizaram o câncer (CA), vitamina D (Vit. D) e/ou seus mecanismos como objetivo principal de estudo. Como critério de exclusão, os artigos duplicados; artigos teóricos ou de revisão, teses e dissertações, livros e/ou capítulos de livros; pesquisas que abordavam a ingesta e/ou estudo de demais nutrientes ou substâncias que não principal ou exclusivamente a Vit. D; e aquelas exclusivamente in vitro.

As táticas para a pesquisa e seleção dos artigos envolveram a associação dos descritores e palavras-chaves para todas as bases de dados, na seguinte forma: (“Vitamin D” OR Calcitriol) AND (Oncogenesis OR Carcinogenesis) AND (Cancer OR Neoplasms). Foram selecionados e aplicados os filtros de idiomas, datas de publicações e texto completo. Seguiu-se com a leitura dos títulos e resumos, classificação e, por fim, leitura na íntegra dos eleitos com a seleção dos dados pertinentes. Um total de 391 publicações foram identificadas, sendo que 45 foram consideradas para a leitura na íntegra. Após a leitura categórica, 19 artigos foram selecionados para este estudo. Na tabela 1, se pode observar detalhadamente as quantidades de artigos encontrados, descartados e selecionados após cada etapa. 
Tabela 1. Procedimentos de leitura.

\begin{tabular}{c|c|c|c|c|c}
\hline $\begin{array}{c}\text { Bases de } \\
\text { dados }\end{array}$ & $\begin{array}{c}\text { Número de artigos } \\
\text { encontrados }\end{array}$ & $\begin{array}{c}\text { Artigos duplicados e } \\
\text { não considerados na } \\
\text { atual base de dados }\end{array}$ & $\begin{array}{c}\text { Leitura dos } \\
\text { resumos }\end{array}$ & $\begin{array}{c}\text { Leitura na } \\
\text { íntegra }\end{array}$ & $\begin{array}{c}\text { Selecionados para a } \\
\text { escrita do artigo }\end{array}$ \\
\hline BVS & 304 & 0 & 304 & 33 & \\
PubMed & 87 & 27 & 60 & 12 & 3 \\
Total & 391 & 27 & 364 & 45 & 16 \\
\hline
\end{tabular}

Fonte: Dados da pesquisa.

\section{Resultados e Discussão}

Na Tabela 2, é possível observar, conforme o estudo, o órgão acometido pelo câncer (CA), o objetivo do estudo e seus participantes, a metodologia e os principais resultados sobre a influência da vitamina D (Vit. D) sobre a oncogênese nos cânceres do trato gastrointestinal (TGI), e na Tabela 3, a influência da Vit. D sobre o CA em órgãos distintos.

Tabela 2. Principais resultados em relação a influência da Vit. D sobre os cânceres que acometem o TGI.

\begin{tabular}{|c|c|c|c|c|}
\hline Estudo & $\begin{array}{c}\text { Órgão } \\
\text { acometido }\end{array}$ & $\begin{array}{c}\text { Objetivo e participantes do } \\
\text { estudo }\end{array}$ & Metodologia do estudo & Principais resultados \\
\hline Yang et al. (2017) & $\begin{array}{c}\text { CA } \\
\text { colorretal }\end{array}$ & $\begin{array}{l}\text { Objetivo: Analisar o valor } \\
\text { prognóstico da proteína de } \\
\text { ligação da Vit. D, 25(OH)D } \\
\text { total, livre e biodisponível em } \\
\text { pacientes com CA colorretal } \\
\text { entre os estágios I-III. } \\
\text { Participantes: ( } \mathrm{n}=206) \\
\text { pacientes com CA entre os } \\
\text { estágios I-III (n=131 homens } \\
\text { e } n=75 \text { mulheres). }\end{array}$ & $\begin{array}{l}\text { Dosagem sérica pré-cirúrgica } \\
\text { ( } 7 \text { dias antes da cirurgia) de } \\
25(\mathrm{OH}) \mathrm{D} \text {, proteína de } \\
\text { ligação da Vit. D e albumina. }\end{array}$ & $\begin{array}{l}\text { Níveis } \uparrow \text { de } 25(\mathrm{OH}) \mathrm{D} \text { livre e } \\
\text { biodisponível foram associados } \\
\text { à melhor sobrevida global. A } \\
25(\mathrm{OH}) \mathrm{D} \text { livre foi considerada } \\
\text { um fator prognóstico } \\
\text { independente para a sobrevida, } \\
\text { podendo ser um biomarcador de } \\
\text { monitoramento para tal. A } \\
\text { proteína de ligação à Vit. D não } \\
\text { foi relacionada à sobrevida. }\end{array}$ \\
\hline Xin et al. (2017) & $\begin{array}{c}\text { CA } \\
\text { colorretal }\end{array}$ & $\begin{array}{l}\text { Objetivo: Identificar se a vit. } \\
\text { D3 possui efeito preventivo na } \\
\text { carcinogênese associada à } \\
\text { colite. } \\
\text { Participantes: } \\
\text { Estudo 1: ratos machos } \\
\text { C57BL/6 de } 6 \text { a } 8 \text { semanas, } \\
\text { sendo (n=5) controles e uma } \\
\text { média (n=11) por grupo } \\
\text { testado. } \\
\text { Estudo 2: Células de CA de } \\
\text { cólon humano SW480. }\end{array}$ & $\begin{array}{l}\text { Estudo 1: o CA foi induzido } \\
\text { i.p. por 12,5mg/kg de AOM } \\
\text { e uma semana depois, por } \\
2,5 \% \text { (peso/volume) de DSS } \\
\text { em água por } 5 \text { dias. } \\
\text { Alimentados com dieta } \\
\text { padrão. Cada grupo recebeu } \\
\text { dosagens diferentes de Vit. D } \\
\text { (15, 30 ou 60UI) i.g. 3x por } \\
\text { semana, antes ou após da } \\
\text { adm. dos cancerígenos. } \\
\text { Sacrificados na } 14{ }^{\circ} \text { semana. } \\
\text { Analisados níveis séricos de } \\
\text { 25(OH)D3, cálcio e } \\
\text { creatinina. } \\
\text { Estudo } 2: \text { In vitro. A } \\
\text { proliferação celular analisada } \\
\text { a partir do tratamento com } \\
\text { [ ] variadas de } 1,25(O H) 2 D 3 \\
\text { (1 a } 100 \text { nM). Ensaio de } \\
\text { transfecção transiente e } \\
\text { luciferase foi realizado a } \\
\text { partir do tratamento com } \\
\text { 1,25(OH)2D3 (100nmol/L). } \\
\text { RNA total do tecido e células } \\
\text { cancerosas foi isolado e } \\
\text { analisado. }\end{array}$ & $\begin{array}{l}\text { Estudo 1: A adm. de Vit. D } 2 \\
\text { semanas antes da adm. de AOM } \\
\text { (15, } 30 \text { e } 60 \mathrm{UI}) \downarrow \text { em, } \\
\text { respectivamente, } 33 \%, 63 \% \text { e } \\
42 \% \text { o n. e a carga neoplásica, e } \\
\text { em } 17 \%, 35 \%, 41 \% \text { a } \\
\text { proliferação das células no } \\
\text { cólon. 60UI de Vit. D após o } \\
\text { tratamento com DSS } \downarrow 59 \% \text { o } \\
\text { n. e a carga de tumores, e } 36 \% \text { a } \\
\text { proliferação celular no cólon. A } \\
\text { Vit. D3 } \downarrow \text { a ativação da } \beta- \\
\text { catenina, } \uparrow \text { E-caderina, } \\
\text { sinalizando a interposição da E- } \\
\text { caderina na proteção da Vit. D } \\
\text { no CA colorretal. } \\
\text { Estudo } 2 \text { : O tratamento com } \\
\text { 1,25(OH)2D3 (independente do } \\
\text { tempo e da dose) } \downarrow \text { o } \\
\text { crescimento celular colônico. }\end{array}$ \\
\hline
\end{tabular}




\begin{tabular}{|c|c|c|c|c|}
\hline Eom et al. (2018) & CA gástrico & $\begin{array}{l}\text { Objetivo: Avaliar o papel da } \\
\text { Vit. D no desenvolvimento do } \\
\text { CA gástrico, determinando os } \\
\text { efeitos de ingestão, e } \\
\text { polimorfismos genéticos } \\
\text { associados à Vit. D com } \\
\text { incidência de CA. } \\
\\
\text { Participantes: ( } \mathrm{n}=1.430) \\
\text { pacientes recém- } \\
\text { diagnosticados com CA } \\
\text { (n=715) e controles }(\mathrm{n}=715) \text {. } \\
\text { Em ambos grupos, }(\mathrm{n}=455) \\
\text { homens e (n=260) mulheres. }\end{array}$ & $\begin{array}{l}\text { Por QFA, foi analisado a } \\
\text { ingesta de Vit. D e por } \\
\text { dosagem sérica, os níveis } \\
\text { circulantes de } 25(\mathrm{OH}) \mathrm{D} 3 \mathrm{e} \\
1,25(\mathrm{OH}) 2 \mathrm{D} 3 \text {. A análise da } \\
\text { genotipagem foi realizada } \\
\text { através do DNA genômico. }\end{array}$ & $\begin{array}{l}\text { Não houve } \neq \text { significativa entre } \\
\text { a ingestão de Vit. D e o risco de } \\
\text { CA entre os participantes. } \\
\text { Houve associação positiva entre } \\
\text { os níveis circulantes de } \\
25(\mathrm{OH}) \mathrm{D} 3 \text { e a ingestão } \\
\text { dietética. Sem interações } \\
\text { relevantes entre a ingestão de } \\
\text { Vit. D e os polimorfismos do } \\
\text { RVD e da proteína que interage } \\
\text { com a tioredoxina. A ingestão } \\
\text { de Vit. D não foi relacionada } \\
\text { com a oncogênese e } \\
\text { polimorfismos. }\end{array}$ \\
\hline $\begin{array}{l}\text { McCullough } \\
\text { et al. (2019) }\end{array}$ & $\begin{array}{c}\text { CA } \\
\text { colorretal }\end{array}$ & $\begin{array}{c}\text { Objetivo: Examinar a } \\
\text { associação entre } 25(\mathrm{OH}) \mathrm{D} \\
\text { circulante e a incidência de } \\
\text { CA colorretal subsequente em } \\
17 \text { coortes prospectivas. } \\
\\
\text { Participantes: } \\
\text { Grupo 1: pacientes com CA } \\
\text { (n=5.706); } \\
\text { Grupo 2: controles ( } \mathrm{n}=7.107) \text {. } \\
\text { Coortes com no mínimo } \\
(\mathrm{n}=50) \text { homens e }(\mathrm{n}=50) \\
\text { mulheres. }\end{array}$ & $\begin{array}{l}\text { Avaliação dos níveis séricos } \\
\text { de } 25(\mathrm{OH}) \mathrm{D} \text { no } \\
\text { pré-diagnóstico para aqueles } \\
\text { com CA, e em momento } \\
\text { independente para os } \\
\text { controles. }\end{array}$ & $\begin{array}{c}\text { A deficiência de Vit. D } \\
\text { (<30nmol/L) foi associada a } \\
>31 \% \text { de chances de } \\
\text { acometimento por CA, e os } \\
\text { níveis entre } 75-87,5 \mathrm{nmol} / \mathrm{L} \text { com } \\
<19 \% \text { e } 87,5-100 \mathrm{nmol} / \mathrm{L} \text { com } \\
<27 \% \text { de chances. Em cada } \\
\text { acréscimo de } 25 \mathrm{nmol} / \mathrm{L}, \text { as } \\
\text { mulheres apresentaram }<19 \% \text { e } \\
\text { os homens }<7 \% \text { de risco. }\end{array}$ \\
\hline $\begin{array}{l}\text { Vincent-Chong, et al. } \\
\text { (2019) }\end{array}$ & $\begin{array}{l}\text { CA } \\
\text { oral }\end{array}$ & $\begin{array}{l}\text { Objetivo: Elencar os efeitos } \\
\text { do calcitriol no início e } \\
\text { progressão do CCE. } \\
\text { Participantes: Ratos C57BL/6 } \\
\text { fêmeas com } 15 \text { semanas de } \\
\text { idade ( } \mathrm{n}=10 \text { no estudo } 1 \mathrm{e} \\
\text { n=19 no estudo } 2 \text { ). }\end{array}$ & $\begin{array}{c}\text { Dieta com 1000UI de Vit. } \\
\text { D3. Indução do CA por } \\
\text { 4NQO por } 16 \text { semanas. } \\
\text { Estudo 1: } \\
\text { Grupo 1: solução salina } \\
\text { tamponada com fosfato de } \\
\text { Dulbecco; } \\
\text { Grupo 2: calcitriol }(0,1 \mu \mathrm{g} \\
\text { i.p.) 3x por semana. } \\
\text { Estudo 2: } \\
\text { Grupo 1: calcitriol }(0,1 \mu \mathrm{g} \\
\text { i.p.) 3x na semana e } \\
\text { cancerígeno. } \\
\text { Grupo 2: calcitriol }(0,1 \mu \mathrm{g} \\
\text { i.p.) 3x na semana por } 10 \\
\text { semanas, após as } 16 \text { doses do } \\
\text { cancerígeno. } \\
\text { Grupo 3: calcitriol }(0,1 \mu \mathrm{g} \\
\text { i.p.) 3x na semana por } 26 \\
\text { semanas após o cancerígeno. } \\
\text { Avaliações: ressonância } \\
\text { magnética, metabólitos de } \\
\text { Vit. D, reação em cadeia da } \\
\text { polimerase quantitativa, } \\
\text { histológica e } \\
\text { imunohistoquímica para } \\
\text { elencar o RVD, CYP24A1 e } \\
\text { proteína Ki67. }\end{array}$ & $\begin{array}{l}\text { Com ênfase nos } 2 \text { estudos, o } \\
\text { tratamento com calcitriol por } 16 \\
\text { semanas resultou na inibição da } \\
\text { oncogênese, havendo } \downarrow \text { de } 57 \% \\
\text { das lesões pré-malignas. O } \\
\text { tratamento por } 26 \text { semanas } \\
\text { resultou no } \uparrow \text { de CYP24A1 } \\
\text { renal, níveis séricos de } \\
\text { 1,25(OH)2D3 } \downarrow \text { e > incidência } \\
\text { de CCE invasivo. A ação do } \\
\text { calcitriol depende do biênio } \\
\text { estágio de intervenção e } \\
\text { duração da exposição. } \\
\text { Independentemente do tempo } \\
\text { de tratamento e grupo, houve } \uparrow \\
\text { do RVD, CYP24A1 e proteína } \\
\text { Ki67 em epitélios displásicos. }\end{array}$ \\
\hline $\begin{array}{l}\text { Suksawatamnuay } \\
\text { et al. }(2020)\end{array}$ & $\begin{array}{c}\text { CA } \\
\text { colorretal }\end{array}$ & $\begin{array}{l}\text { Objetivo: Avaliar se os PNUs } \\
\text { comuns e os haplótipos do } \\
\text { gene RVD contribuem para a } \\
\text { carcinogênese colorretal na } \\
\text { população tailandesa. } \\
\\
\text { Participantes: Grupo 1: } \\
\text { controles com cólon normal e } \\
\text { sem pólipos ( } \mathrm{n}=182, \text { sendo } \\
\mathrm{n}=103 \text { homens e } \mathrm{n}=79 \\
\end{array}$ & $\begin{array}{c}\text { Dosagem sérica de } 25(\mathrm{OH}) \mathrm{D} \\
\text { total e análise dos genótipos } \\
\text { RVD através do DNA } \\
\text { genômico extraído de } \\
\text { leucócitos. }\end{array}$ & $\begin{array}{c}\text { 76,1\% daqueles com CA e } \\
79,9 \% \text { dos controles } \\
\text { apresentaram deficiência de Vit. } \\
\text { D. Ambos apontaram } \\
\text { proporções semelhantes na } \\
\text { frequência dos alelos e } \\
\text { genótipos dos PNUs do RVD, } \\
\text { não havendo associação com o } \\
\text { desenvolvimento de CA. O } \\
\text { haplótipo GGGT foi o mais }\end{array}$ \\
\hline
\end{tabular}




\begin{tabular}{|c|c|c|c|c|}
\hline & & $\begin{array}{c}\text { mulheres); } \\
\text { Grupo 2: pacientes recém } \\
\text { diagnosticados com CA } \\
(\mathrm{n}=182, \text { sendo } \mathrm{n}=59 \text { homens e } \\
\mathrm{n}=123 \text { mulheres). }\end{array}$ & & $\begin{array}{c}\text { frequente em ambos os grupos e } \\
\text { o AGGT o mais associado à } \downarrow \\
\text { do risco de CA. }\end{array}$ \\
\hline Zhang et al. (2020) & $\begin{array}{c}\text { CA } \\
\text { colorretal }\end{array}$ & $\begin{array}{c}\text { Objetivo: Elucidar os } \\
\text { mecanismos do RVD na } \\
\text { manutenção da homeostase } \\
\text { intestinal e microbioma na } \\
\text { proteção contra a } \\
\text { tumorogênese intestinal. } \\
\text { Participantes: Ratos machos e } \\
\text { fêmeas; } \\
\text { Grupo 1: (n=30) com o gene } \\
\text { RVD nocauteado - } \downarrow- \\
\text { (knockout), do tipo VDR } \\
\text { Grup; } \\
\text { Grupo 2: }(\mathrm{n}=30) \text { controles. }\end{array}$ & $\begin{array}{l}\text { O CA foi induzido i.p. pelo } \\
\text { cancerígeno AOM } \\
\text { (10mg/kg) e } 3 \text { ciclos de } 2 \% \\
\text { de DSS em água potável. } \\
\text { Foram realizadas culturas de } \\
\text { células, sendo utilizado } \\
\text { amostras de CA de cólon } \\
\text { humano e colonoides } \\
\text { derivados de células-tronco. }\end{array}$ & $\begin{array}{c}\text { A } \downarrow \text { do RVD } \uparrow \text { o n. de tumores, } \\
\text { alterando a localização do cólon } \\
\text { distal para o proximal; } \\
\text { modificou o perfil bacteriano } \\
\text { para vulnerável e } \uparrow \text { a secreção } \\
\text { de ácidos biliares secundários. } \\
\text { O RVD ao se ligar ao JAK2, } \\
\text { resulta na regulação } \\
\text { transcricional do JAK2. A } \downarrow \text { do } \\
\text { RVD resulta em hiperfunção do } \\
\text { JAK2 em resultado à disbiose } \\
\text { intestinal. A constância de RVD } \\
\text { e microbioma intestinal atuam } \\
\text { na prevenção ou influenciando } \\
\text { na oncogênese colorretal. }\end{array}$ \\
\hline $\begin{array}{l}\text { Messaritakis } \\
\text { et al. (2020) }\end{array}$ & $\begin{array}{c}\text { CA } \\
\text { colorretal }\end{array}$ & $\begin{array}{c}\text { Objetivo: Investigar a } \\
\text { relevância dos PNUs do gene } \\
\text { RVD rs731236 (TaqI), } \\
\text { rs7975232 (ApaI), rs2228570 } \\
\text { (FokI) e rs1544410 (BsmI) } \\
\text { para a carcinogênese } \\
\text { colorretal. } \\
\text { Participantes: Grupo 1: } \\
\text { (n=397) pacientes ( }=246 \\
\text { homens e } \mathrm{n}=151 \text { mulheres) } \\
\text { em estágios II/III operável } \\
(\mathrm{n}=202) \text { e em estágio IV } \\
\text { (n=195). } \\
\text { Grupo 2: (n=140) controles, } \\
\text { sendo indivíduos saudáveis } \\
\text { (n=100) e com adenomas de } \\
\text { cólon, mas sem CA (n=40). }\end{array}$ & $\begin{array}{l}\text { Análises realizadas através } \\
\text { das células mononucleares } \\
\text { do sangue periférico. } \\
\text { Extração do DNA genômico, } \\
\text { genotipagem do RVD e } \\
\text { receptor Toll-like, e inspeção } \\
\text { mutacional do } \\
\text { oncogene KRAS. }\end{array}$ & $\begin{array}{c}\text { Houve associação relevante } \\
\text { entre CA e os PNUs do gene } \\
\text { RVD TaqI, ApaI, FokI e BsmI. } \\
\text { Pacientes com genótipos } \\
\text { homozigotos mutantes (aa, bb, } \\
\text { ff ou tt) foram > propensos à } \\
\text { doença, ao estágio > avançado } \\
\text { (IV) e à < sobrevida. } \\
\text { Polimorfismos se relacionaram } \\
\text { com mutações oncogênicas no } \\
\text { gene KRAS e variações } \\
\text { genéticas do receptor Toll-like } \\
\text { (TLR2, TLR4 e TLR9). } \\
\text { Variações dos polimorfismos } \\
\text { do RVD se correlacionaram } \\
\text { com o desenvolvimento e } \\
\text { progressão do CA e sobrevida } \\
\text { dos pacientes. }\end{array}$ \\
\hline Kwak e Paik (2020) & CA gástrico & $\begin{array}{c}\text { Objetivo: Determinar a } \\
\text { relação entre as [ ] de Vit. } D \text { e } \\
\text { a prevalência de CA gástrico } \\
\text { na população coreana. } \\
\\
\text { Participantes: ( } \mathrm{n}=33.119 \text { ) } \\
\text { coreanos. Grupo 1: pacientes } \\
\text { com CA ( } \mathrm{n}=218 \text {, sendo } \mathrm{n}=138 \\
\text { homens e } \mathrm{n}=80 \text { mulheres); } \\
\text { Grupo 2: controle, sem o } \\
\text { diagnóstico de CA ( } \mathrm{n}=32.901 \text {, } \\
\text { sendo } \mathrm{n}=13.383 \text { homens e } \\
\mathrm{n}=19.518 \text { mulheres). }\end{array}$ & $\begin{array}{l}\text { Dosagem sérica de } 25(\mathrm{OH}) \mathrm{D} \\
\text { em jejum. Classificação das } \\
\text { [ ] foram da seguinte forma: } \\
\quad<12 \mathrm{ng} / \mathrm{mL}=\text { insuficiente; } \\
12-19,9 \mathrm{ng} / \mathrm{mL}=\text { subótimo; } \\
\quad>20 \mathrm{ng} / \mathrm{mL}=\text { suficiente. }\end{array}$ & $\begin{array}{c}\text { Pacientes com CA obtiveram } \\
\text { média de } 17.4 \mathrm{ng} / \mathrm{mL} \text { e os } \\
\text { controles } 17.5 \mathrm{ng} / \mathrm{mL} \text {, sendo } \\
\text { classificados como subótimo. } \\
\text { Ao parear os grupos conforme } \\
\text { classificações de [ ] de Vit. D às } \\
\text { características individuais } \\
\text { (sexo, idade, entre outros), } \\
\text { aqueles com } \\
>\text { [ ] de Vit. D foram associados } \\
\text { a uma < razão de chances para } \\
\text { o desenvolvimento de CA } \\
\text { gástrico. }\end{array}$ \\
\hline Verma et al. (2020) & $\begin{array}{l}\text { CA } \\
\text { oral }\end{array}$ & $\begin{array}{l}\text { Objetivo: Investigar o impacto } \\
\text { da Vit. D3 da dieta no início e } \\
\text { progressão do CA oral. } \\
\text { Participantes: Ratos } \\
\text { C57BL/6NCr fêmeas de } 9 \\
\text { semanas de idade, ( }=6 \text { em } \\
\text { cada grupo). }\end{array}$ & $\begin{array}{c}\text { Estudo 1: dietas com } \neq \\
\text { constâncias de Vit. D } \\
(25 \mathrm{UI} / \mathrm{kg}, 100 \mathrm{UI} / \mathrm{kg} \text { ou } \\
10.000 \mathrm{UI} / \mathrm{kg}) \text {. Tumor } \\
\text { induzido por 4NQO } \\
(100 \mu \mathrm{g} / \mathrm{ml}) 1 \mathrm{x} \text { por semana } \\
\text { por } 16 \text { semanas. Analisados } \\
\text { níveis séricos de } \\
\text { 1,25(OH)2D3 e } 25(\mathrm{OH}) \mathrm{D} 3 . \\
\text { Avaliação das lesões } \\
\text { tumorais e imunocolaração } \\
\text { das seções da língua para } \\
\text { análise de RVD, CYP24A1 } \\
\text { e células T CD3. Estudo de }\end{array}$ & $\begin{array}{c}\text { Estudo 1: aqueles tratados com } \\
\text { 100UI/kg apresentaram } \downarrow \text { na } \\
\text { incidência de CCE e células T } \\
\text { CD3 }>\uparrow \text { em relação aos animais } \\
\text { com dietas de } 25 \mathrm{UI} / \mathrm{kg} \text { e } \\
\text { 10.000UI/kg. Níveis séricos de } \\
25(\mathrm{OH}) \mathrm{D} 3>\uparrow \text { entre os tratados } \\
\text { com } 10.000 \mathrm{UI} \text { no início do } \\
\text { experimento, mas obtiveram } \\
\text { uma } \downarrow \text { de } 50 \% \text { no fim, havendo } \\
\text { uma }>\text { incidência de CCE. } \\
\text { Aqueles tratados com } 100 \mathrm{UI} \text { e } \\
\text { 10.000UI apresentaram } \uparrow \text { no } \\
\text { RVD e CYP24A1 em lesões }\end{array}$ \\
\hline
\end{tabular}




\begin{tabular}{l|l|l|c|c}
\hline & & $\begin{array}{c}\text { 26 semanas. } \\
\text { Estudo 2: dieta deficiente em } \\
\text { Vit. D3 com 25UI ou dieta } \\
\text { com 1000UI por 6 semanas. }\end{array}$ & $\begin{array}{c}\text { displásicas de alto grau e CCE } \\
\text { em comparação à língua } \\
\text { normal. } \\
\text { Estudo 2: Com 25UI de } \\
\text { calcitriol, houve a } \downarrow \text { do } \\
\text { crescimento do tumor em } \\
\text { comparação com os controles, } \\
\text { mas náo afetou o crescimento } \\
\text { entre tratados com 1000UI. } \\
\text { Os benefícios do calcitriol a } \\
\text { curto prazo pode ser mais } \\
\text { vantajoso em organismos com } \\
\text { deficiência de Vit. D. }\end{array}$ \\
\hline
\end{tabular}

Nota. CA: câncer. Vit. D: Vitamina D. 25(OH)D/25(OH)D3: 25-hidroxivitamina D. n= número. $\uparrow$ : elevado/aumentado. i. p.: intraperitoneal. mg/kg: miligramas por quilogramas. AOM: azoximetano. \%: porcentagem. DSS: dextran sulfato de sódio. UI: unidades internacionais. i.g: intragástrico. x: vezes. Adm: administração. [ ]: concentração. 1,25(OH)2D3: 1,25-diidroxicolecalciferol. nM: nanômetro. nmol/L: nanomol por litro. RNA: ácido ribonucleico. $\downarrow$ : diminuído/redução. QFA: questionário de frequência alimentar. DNA: ácido desoxirribonucleico. \#: diferença. RVD: receptor de vitamina D. <: menos/menor. >: mais/maior 4NQO: 4-nitroquinolina 1-óxido. $\mu$ g: micrograma CYP24A1: 24hidroxilase. CCE: Carcinoma de Células Escamosa. PNUs: polimorfismos de nucleotídeo único. JAK2: Janus Quinase 2. TaqI: Thermus aquaticus I. ApaI: Acetobacter pasteurianus sub. pasteurianus I. FokI: Flavobacterium okeanokoites I. BsmI: Bacillus stearothermophilus I. TLR2: receptor Toll-like 2. TLR4: receptor Toll-like 4. TLR9: receptor Toll-like 9. ng/mL: nanograma por mililitro.

Fonte: Autores (2020).

Entre os estudos que investigaram a influência da Vit. D sobre os cânceres que acometem o TGI (n=13), expostos na tabela 2, três artigos expuseram os resultados de dois experimentos diferentes cada (Xin et al., 2017; Vincent-Chong et al., 2019; Verma et al., 2020). Dos estudos, 53,85\% ( $n=7)$ elucidaram a relação com o CA de colorretal, 30,77\% (n=4) com CA oral e $15,38 \%(n=2)$ com CA gástrico.

Destaca-se que 84,62\% ( $\mathrm{n}=11)$ dos científicos evidenciaram a importância e influência positiva da Vit. D e seus mecanismos de ação no processo anti-carcinogênese.

Do total de artigos selecionados $(n=10), 60 \%(n=6)$ evidenciaram a possível influência da Vit. D sobre o CA colorretal, onde pacientes com este tipo de CA e que possuíam níveis séricos elevados de 25(OH)D livre e biodisponível apresentam melhor sobrevida global, sendo este marcador considerado um prognóstico de sobrevida (Yang et al., 2017). A administração de Vit. D em diferentes doses resulta na redução significativa do número de tumores, carga neoplásica e proliferação de células cancerígenas no cólon (Xin et al., 2017).

No CA colorretal, a deficiência de Vit. D está ligada a mais chances de acometimento por CA, logo, níveis séricos elevados estão relacionados a menores chances (McCullough et al., 2019). Na perda do receptor de vitamina D (RVD), há um aumento de tumores no cólon proximal, modificando o perfil microbiano, destacando a importância da constância de RVD na prevenção do CA (Zhang et al., 2020). Há uma associação entre o surgimento do CA e polimorfismos de nucleotídeo único (PNUs) do gene RVD e genótipos homozigotos mutantes (Messaritakis et al., 2020). O estudo de Suksawatamnuay et al. (2020) não destacou nenhuma associação significativa entre a Vit. D e a oncogênese, sendo encontrado proporções semelhantes de deficiência, frequência de alelos e genótipos de PNUs do RVD em pacientes com CA e controles.

Nos científicos do CA gástrico $(n=2)$, Eom et al. (2018) refere não ter diferença entre a ingestão oral de Vit. D e o risco de CA, e, ainda, não sofrer influência sobre os PNUs do gene RVD. No estudo de Kwak e Paik (2020) foram encontradas concentrações séricas de Vit. D similares entre pacientes com CA e controles, entretanto, após pareados por características individuais, maiores proporções de Vit. D foram associados a um menor risco de CA gástrico.

Nos selecionados do CA oral $(n=2)$, o tratamento a curto prazo (16 semanas) com vit. D diminuiu a porcentagem de lesões pré-malignas, entretanto, a longo prazo (26 semanas) o nível sérico de Vit. D diminui, ocorrendo aumento na incidência de carcinoma de células escamosas oral (CCE) invasivo, no qual, o efeito protetor da Vit. D depende do biênio tempo e estágio 
de intervenção (Vincent-Chong et al., 2019). Para Verma et al. (2020), os benefícios da administração de Vit. D também estão relacionados a curto prazo e em ínvidos com deficiência, pois dosagens de concentrações diferentes de Vit. D podem resultar em aumento ou redução de lesões de CCE.

Tabela 3. Principais resultados em relação a influência da Vit. D sobre os cânceres que acometem órgãos distintos.

\begin{tabular}{|c|c|c|c|c|}
\hline Estudo & $\begin{array}{c}\text { Órgão } \\
\text { acometido }\end{array}$ & $\begin{array}{c}\text { Objetivo e participantes } \\
\text { do estudo }\end{array}$ & Metodologia do estudo & Principais resultados \\
\hline $\begin{array}{l}\text { Park et al. } \\
\text { (2016) }\end{array}$ & CA de pele & 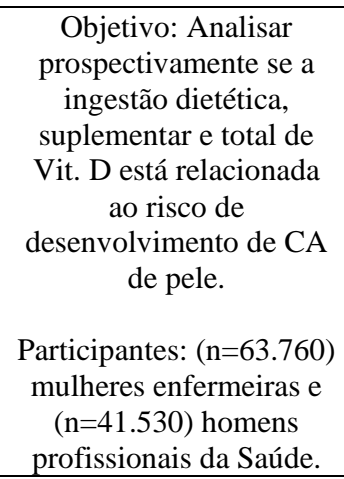 & $\begin{array}{c}\text { A ingestão alimentar de vit. D foi } \\
\text { avaliada por QFA, repetido a cada } 4 \\
\text { anos no decorrer do estudo (duração } \\
\text { total: } 24 \text { anos). O cálculo de ingestão } \\
\text { total de Vit. D considerou a ingestão } \\
\text { dietética, suplementos isolados e } \\
\text { multivitamínicos contento Vit. D. } \\
\text { Bienalmente, os participantes relatavam } \\
\text { possíveis diagnósticos de CBC, CCE e } \\
\text { melanoma. }\end{array}$ & $\begin{array}{c}\text { Durante o estudo houve o } \\
\text { diagnóstico de } 20.840 \text { CBC, } \\
2.329 \text { CCE e } 1.320 \text { casos de } \\
\text { melanoma. A ingestão total de } \\
\text { Vit. D não se relacionou com o } \\
\text { risco de CCE e melanoma, mas } \\
\text { uma > ingestão dietéticas e } \\
\text { suplementar foi modestamente } \\
\text { associada com o } \\
\text { desenvolvimento do CCB. Não } \\
\text { há relação segura entre } \\
\text { ingestão de Vit. D oral e a } \\
\text { prevenção de CA. }\end{array}$ \\
\hline $\begin{array}{l}\text { Kim et al. } \\
\text { (2016) }\end{array}$ & CA de pele & $\begin{array}{l}\text { Objetivo: Investigar o } \\
\text { efeito protetor da } \\
\text { aplicação tópica de Vit. } \\
\text { D no desenvolvimento } \\
\text { do CA de pele causado } \\
\text { pela exposição aos UV. } \\
\text { Participantes: Ratas sem } \\
\text { pelos com } \\
\text { aproximadamente 6-7 } \\
\text { semanas }(n=35) \text {. }\end{array}$ & 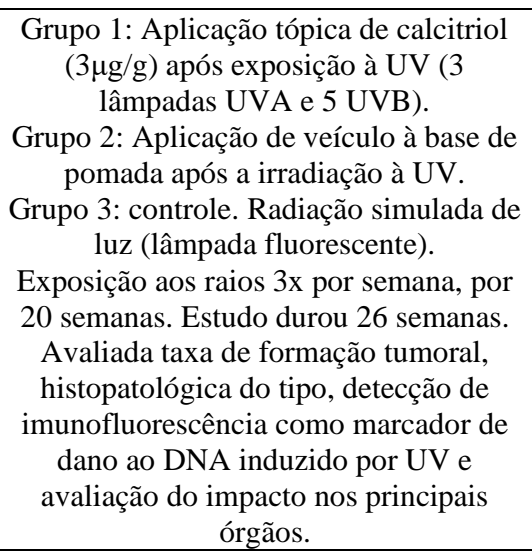 & $\begin{array}{c}\text { Naqueles tratados com } \\
\text { calcitriol e expostos à UV, } \\
\text { houve } \downarrow \text { no número e formação } \\
\text { de tumores < ou >3mm, } \\
\text { malignidade de baixo grau e } \\
\text { atraso na progressão tumoral, } \\
\text { protegendo o dano ao DNA } \\
\text { induzido pelo UV. }\end{array}$ \\
\hline $\begin{array}{l}\text { Orlow et al. } \\
\text { (2016) }\end{array}$ & CA de pele & $\begin{array}{l}\text { Objetivo: Investigar se a } \\
\text { variação genética do } \\
\text { RVD influencia a } \\
\text { sobrevivência em } \\
\text { pacientes com } \\
\text { melanoma. } \\
\text { Participantes: ( } \mathrm{n}=3.566 \text { ) } \\
\text { pacientes ( } \mathrm{n}=2.004 \\
\text { homens e } \mathrm{n}=1.562 \\
\text { mulheres), sendo } \\
\text { (n=2.361) com casos de } \\
\text { melanoma primário } \\
\text { único incidente e } \\
\text { (n=1.205) com } \\
\text { melanoma primário } \\
\text { múltiplo incidente. }\end{array}$ & $\begin{array}{l}\text { Foram realizados a seleção de PNUs do } \\
\text { RVD, extração de DNA, detalhes de } \\
\text { genotipagem e procedimentos de } \\
\text { controle de qualidade e associações entre } \\
\text { os RVD, haplótipos e sobrevivência. }\end{array}$ & $\begin{array}{c}\text { Dos } 38 \text { PNUs do RVD } \\
\text { estudados no melanoma, } 1 \\
\text { polimorfismo foi associado à } \\
\text { espessura, mas não à } \\
\text { sobrevida; } 8 \text { foram } \\
\text { correlacionados à sobrevida; } 5 \\
\text { à morte por melanoma. O } \\
\text { haplótipo C-C-G formado por } \\
\text { rs12370156 - rs2238140 - } \\
\text { rs7305032 foi relacionado à } \\
\text { morte por melanoma. } \\
\text { Alterações no gene RVD pode } \\
\text { influenciar a sobrevivência no } \\
\text { melanoma. }\end{array}$ \\
\hline $\begin{array}{l}\text { Eliassen et al. } \\
\qquad(2016)\end{array}$ & CA de mama & $\begin{array}{l}\text { Objetivo: Examinar se há } \\
\text { associação entre } \\
\text { 25(OH)D e o risco de } \\
\text { CA de mama, e } \\
\text { expressão de tecido } \\
\text { tumoral de RVD e RXR. } \\
\text { Participantes: }(\mathrm{n}=1.506) \\
\text { mulheres com CA de } \\
\text { mama. } \\
\end{array}$ & $\begin{array}{c}\text { O tempo da coleta sanguínea até o } \\
\text { diagnóstico de CA de mama variou de }< \\
1 \text { mês a } 20 \text { anos. Foram analisados os } \\
\text { níveis séricos de } 25(\mathrm{OH}) \mathrm{D} \text {. Dados do } \\
\text { tecido tumoral foram coletados via } \\
\text { prontuário. }\end{array}$ & $\begin{array}{l}\text { Não houve associação entre } \\
\text { níveis de } 25(\mathrm{OH}) \mathrm{D} \text { e risco } \\
\text { cancerígeno. Níveis de } \\
\text { 25(OH)D foram } \\
\text { discordantemente relacionados } \\
\text { ao risco de tumores com alta } \\
\text { expressão de RVD nuclear de } \\
\text { estroma, repetindo-se para a } \\
\text { associação do RXR. } \\
\text { Entretanto, os autores } \\
\end{array}$ \\
\hline
\end{tabular}




\begin{tabular}{|c|c|c|c|c|}
\hline & & & & $\begin{array}{l}\text { associaram que mulheres com } \\
\text { níveis > de } 25(\mathrm{OH}) \mathrm{D} \text { no verão, } \\
\text { comparando com as de níveis } \\
<\text {, possuíram risco } \downarrow \text { para CA } \\
\text { de mama. }\end{array}$ \\
\hline $\begin{array}{c}\text { Spath et al. } \\
\text { (2017) }\end{array}$ & CA de pele & $\begin{array}{c}\text { Objetivo: Elucidar os } \\
\text { efeitos biológicos de } \\
\text { 1,25(OH)2D3 em } \\
\text { modelos experimentais } \\
\text { de melanoma. } \\
\text { Participante: } \\
\text { Estudo 1: ( } \mathrm{n}=105) \\
\text { pacientes com melanoma } \\
\text { (n=62 mulheres e } \mathrm{n}=43 \\
\text { homens). ( } \mathrm{n}=101) \\
\text { indivíduos saudáveis de } \\
\text { ambos os sexos. } \\
\text { Estudo 2: In vitro. } \\
\text { Linhas celulares } \\
\text { derivadas de melanoma } \\
\text { metastático (VAG, FOR, } \\
\text { IR6, 1007, MAR e LOJ). } \\
\text { Estudo 3: ratos nus Balb- } \\
\mathrm{c}, \text { de 4-5 semanas } \\
\text { ( } \mathrm{n}=36 \text { ). }\end{array}$ & 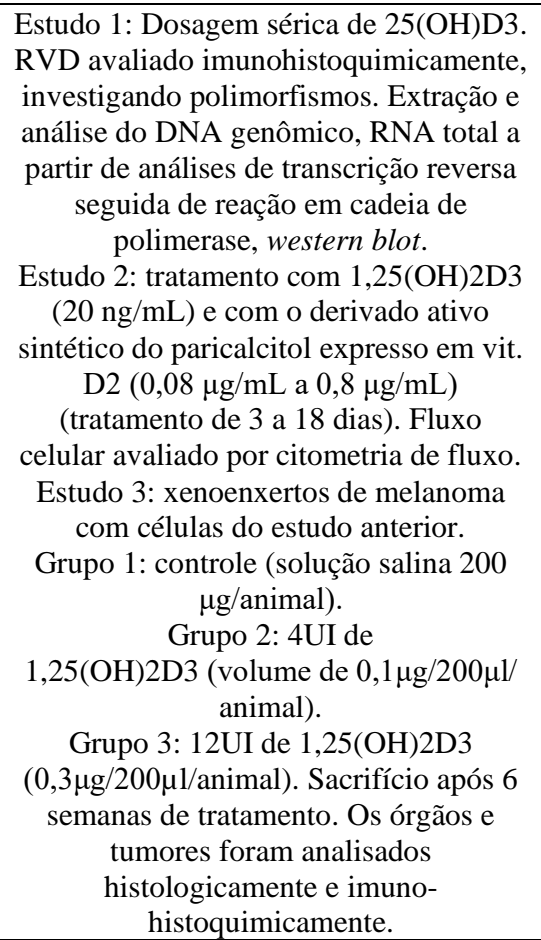 & $\begin{array}{l}\text { 94\% dos portadores de CA } \\
\text { apresentavam níveis } \downarrow \text { de } \\
25(\mathrm{OH}) \mathrm{D} 3 \text {, e dos } 6 \% \text { com } \\
\text { níveis } \uparrow, 5 \% \text { possuíam } \\
\text { melanoma micro invasivo. In } \\
\text { vitro e in vivo, o tratamento } \\
\text { com 1,25(OH)2D3 apresentou } \\
\text { efeitos antiproliferativos, } \\
\text { atenuando a expressão de } \\
\text { moléculas regulatórias } \\
\text { importantes do ciclo celular, } \\
\text { resultando na parada na fase } \\
\text { G1 e G2 a partir do bloqueio } \\
\text { das linhas celulares de } \\
\text { melanoma tumorigênico VAG, } \\
\text { IR6 e } 1007 \text {. }\end{array}$ \\
\hline $\begin{array}{l}\text { Haznadar et } \\
\text { al. (2018) }\end{array}$ & CA de pulmão & $\begin{array}{c}\text { Objetivo: Investigar a } \\
\text { associação entre a Vit. } D \\
\text { e o CA de pulmão. } \\
\text { Participantes: } \\
\text { Grupo 1: (n=406) casos } \\
\text { de CA de pulmão ( } \mathrm{n}=234 \\
\text { homens e } \mathrm{n}=192 \\
\text { mulheres) e (n=437) } \\
\text { controles ( } \mathrm{n}=234 \text { homens } \\
\text { e } \mathrm{n}=203 \text { mulheres). } \\
\text { Grupo 2: (n=194) } \\
\text { indivíduos, sendo (n=90) } \\
\text { casos de CA de pulmão e } \\
\text { (n=104) controles, sem } \\
\text { especificações de gênero. }\end{array}$ & $\begin{array}{l}\text { Os níveis séricos de } 25(\mathrm{OH}) \mathrm{D} 3 \text { foram } \\
\text { aferidos no grupo } 1 \text { e } 1,25(\mathrm{OH}) 2 \mathrm{D} 3 \text { no } \\
\text { grupo 2. A quantificação dos } \\
\text { metabólitos foi realizada a partir da } \\
\text { cromatografia líquida de ultra } \\
\text { performance acoplada à espectrometria } \\
\text { de massa em tandem. O DNA genômico } \\
\text { foi extraído para genotipagem dos } \\
\text { PNUs. }\end{array}$ & $\begin{array}{c}\text { Níveis crescentes de } \\
\text { 25(OH)D3 e 1,25(OH)2D3 } \\
\text { foram inversamente associados } \\
\text { ao CA. Níveis } \uparrow \text { de Vit. D3 são } \\
\text { protetoras no CA de pulmão. A } \\
\text { Vit. D2 não se associou com o } \\
\text { CA. } 27 \text { PNUs (13 relacionados } \\
\text { com níveis de Vit. D) - } \\
\text { CYP24A1 e RVD estavam } \\
\text { associados ao CA, expressão } \\
\text { de mRNA afetada e níveis de } \\
\text { Vit. D. Genótipos } \downarrow \\
\text { heterozigotos e homozigotos } \\
\text { rs10623012 associaram-se ao } \\
\text { efeito protetor no CA. }\end{array}$ \\
\hline $\begin{array}{l}\text { Makarova et } \\
\text { al. (2018) }\end{array}$ & CA de mama & $\begin{array}{c}\text { Objetivo: Avaliar os } \\
\text { efeitos de UV e Vit. D3 } \\
\text { no CA de mama. } \\
\text { Participantes: } \\
\text { Ratos transgênicos de um } \\
\text { modelo de CA mamário } \\
\text { C3(1)/SV40 Tag de } 6 \\
\text { semanas. Ratos } \\
\text { NOD/SCID. } \\
\text { Estudo 1: ( } \mathrm{n}=3-5 \text { ratos } \\
\text { por grupo); } \\
\text { Estudo 2: }(\mathrm{n}=3-5 \text { ratos } \\
\text { por grupo); } \\
\text { Estudo 3: (n=9 ratos por } \\
\text { grupo); } \\
\text { Estudo 4: } 32 \text { ratos ( } \mathrm{n}=26) \\
\text { receberam células M28 e }\end{array}$ & $\begin{array}{c}\text { Estudo 1: dieta pobre em Vit. D após o } \\
\text { desmame. Diferentes grupos recebendo } \\
\text { D3: 0UI/kg, } 1.500 \mathrm{UI} / \mathrm{kg}, 1.000 \mathrm{UI} / \mathrm{kg} \text {, ou } \\
\text { 20.000UI/kg. } \\
\text { Estudo 2: ratos raspados semanalmente e } \\
\text { expostos 3x por semana a uma } \\
\text { constância de } 350 \mathrm{~mJ} / \mathrm{cm}^{2} \text { de UV. } \\
\text { Grupo } 1 \text { (transgênicos): UV da } 6^{\circ} \\
\text { semana de idade até a eutanásia ou até a } \\
\text { idade em que o } 1^{\circ} \text { tumor se tornou } \\
\text { palpável. } \\
\text { Grupo } 2 \text { (NOD/SCID): tratados a partir } \\
\text { do momento em que o > diâmetro do } \\
\text { tumor atingiu } 1 \mathrm{~cm} \text { até a eutanásia. Para } \\
\text { estudar dímeros de ciclopirimidina, } 1 \\
\text { rato foi exposto a uma dose de UV, } \\
\text { sacrificado e analisado. } \\
\text { Estudo 3: Os transgênicos foram tratados }\end{array}$ & $\begin{array}{c}\text { Estudo 1: não houve alterações } \\
\text { significativa no n. de tumores } \\
\text { palpáveis ou idade do } \\
\text { surgimento do } 1^{\circ} \text { tumor, } \\
\text { entretanto, a vit. D3 via oral } \uparrow \\
\text { os níveis séricos de } 25(\mathrm{OH}) \mathrm{D} 3 \text {. } \\
\text { Estudo } 2 \text { : tratamento com UV } \\
\text { iniciado na } 6^{\circ} \text { semana } \uparrow \text { a } \\
\text { sobrevida global e } \downarrow \text { o n. de } \\
\text { tumores mamários palpáveis. O } \\
\text { tratamento iniciado após o } \\
\text { surgimento do } 1^{\circ} \text { tumor } \\
\text { palpável teve pouco ou } \\
\text { nenhum efeito na sobrevida } \\
\text { global ou n. de tumores. Se } \\
\text { iniciada na } 6^{\circ} \text { semana, UV } \downarrow \text { a } \\
\% \text { de glândulas mamárias da } 9^{\circ} \\
\text { a } 13^{\circ} \text { semana. } \mathrm{O} \text { UV } \downarrow \text { a }\end{array}$ \\
\hline
\end{tabular}




\begin{tabular}{|c|c|c|c|c|}
\hline & & (n=6) células M6. & $\begin{array}{l}\text { com colecalciferol topicamente } \\
(0,38 \mu \mathrm{g} / \mathrm{dia}) \text { por } 5 \text { dias, durante } 6 \\
\text { semanas. Os controles receberam } \\
\text { acetona tópica. Os NOD/SCID } \\
\text { receberam } 3,8 \mu \mathrm{g} / \text { dia de colecalciferol a } \\
\text { partir do momento em que o tumor } \\
\text { atingiu } 1 \mathrm{~cm} \text { até a eutanásia. } \\
\text { Estudo } 4 \text { : células de carcinoma mamária } \\
\text { de ratos transgênicos injetadas em } \\
\text { NOD/SCID. Dieta com [ ] normal de vit. } \\
\text { D3. Quando o tumor atingiu 1cm de } \\
\text { diâmetro, receberam UV ou controle, } \\
\text { tópico com D3 ou acetona. Houve } \\
\text { análise microscópica dos tumores; } \\
\text { imunohistoquímica; citometria de fluxo } \\
\text { de apoptose; e sorológica de Vit. D3 e } \\
25(\mathrm{OH}) \mathrm{D} 3 \text {. }\end{array}$ & $\begin{array}{c}\text { proliferação celular em } \\
\text { amostras histológicas com } \\
\text { carcinoma ductal in situ. } \\
\text { Estudo 3: D3 topicamente } \uparrow \text { os } \\
\text { níveis de } 25(\mathrm{OH}) \mathrm{D} 3 \text {, mas não } \\
\text { afetou o início da tumorigênese } \\
\text { mamária. } \\
\text { Estudo 4: no aloenxerto, houve } \\
\text { a inibição do crescimento } \\
\text { tumoral a partir do tratamento } \\
\text { com UV, já no tratamento } \\
\text { tópico, não observou-se } \downarrow \\
\text { significativa no crescimento } \\
\text { tumoral, apesar do } \uparrow \text { nos níveis } \\
\text { circulantes de D3. Ao todo, UV } \\
\text { pode exercer efeitos anticâncer. }\end{array}$ \\
\hline $\begin{array}{l}\text { Horas et al. } \\
\text { (2019) }\end{array}$ & CA de mama & $\begin{array}{l}\text { Objetivo: Identificar o } \\
\text { papel do RVD na } \\
\text { metástase óssea do CA } \\
\text { de mama. } \\
\\
\text { Participantes: Ratos } \\
\text { fêmeas de Balb/c nu/nu } \\
\text { de metástase sistêmica } \\
\text { Estudo } 1:(\mathrm{n}=22), \text { sendo } \\
\text { grupo teste }(\mathrm{n}=11) \text { e } \\
\text { controle }(\mathrm{n}=11) \text {. } \\
\text { Estudo } 2:(\mathrm{n}=51), \text { sendo } \\
\text { grupo teste }(\mathrm{n}=26) \text { e } \\
\text { controle }(\mathrm{n}=25) \text {. }\end{array}$ & $\begin{array}{l}\text { In vitro: As células MDA-MB-231 } \\
\text { tiveram o RVD silenciado. O RNA total } \\
\text { de células tumorais foi isolado e os } \\
\text { níveis de mRNA de GADPH, RVD e } \\
\text { CYP24A1 humanos foram avaliados } \\
\text { quanto à expressão gênica. } \\
\text { In vivo: receberam linha celular de CA } \\
\text { de mama. } \\
\text { Estudo 1: linha de células cancerígenas } \\
\text { com o RVD silenciado e células normais } \\
\text { como controle. Foram fotografados via } \\
\text { imagem de bioluminescência e realizado } \\
\text { raio-X a cada } 5 \text { dias até o dia } 35 . \\
\text { Estudo } 2: \text { mesmas células do } \\
\text { experimento } 1, \text { sendo fotografados nos } \\
\text { dias } 3,7,14,21 \text { e } 28 \text {. Subgrupo } \\
\text { sacrificado nos mesmos dias seguido de } \\
\text { análise morfológica das tíbias e fêmures. } \\
\text { Análises de imagem por } \\
\text { bioluminescência, radiografia, } \\
\text { tomografia computadorizada, histologia, } \\
\text { histometria e imuno-histoquímica. }\end{array}$ & $\begin{array}{l}\text { A Perda do RVD } \uparrow \text { a metástase } \\
\text { de células do CA de mama } \\
\text { MDA-MB-231 para o osso, } \\
\text { originando tumor esquelético, } \\
\text { disseminação celular tumoral, } \\
\text { formação de colônias tumorais, } \\
\uparrow \text { da sobrevivência no osso, } \\
\text { indução da transição de células } \\
\text { epiteliais para mesenquimais, } \downarrow \\
\text { da ß-catenina, E-caderina e F- } \\
\text { actina, e } \uparrow \text { na expressão da } \\
\text { proteína vimentina (proteínas } \\
\text { envolvidas na adesão, } \\
\text { proliferação e organização do } \\
\text { citoesqueleto). Ao todo, a } \downarrow \text { da } \\
\text { expressão do RVD em tecidos } \\
\text { cancerígenos humano de mama } \\
\text { está associada a um } \uparrow \text { no grau } \\
\text { de tumor e tipos de tumores } \\
\text { mais agressivos. }\end{array}$ \\
\hline
\end{tabular}

Nota. CA: câncer. Vit. D: Vitamina D. n: número. QFA: questionário de frequência alimentar. CBC: carcinoma basocelular. CCE: carcinoma de células escamosas. $>$ : maior. UV: raios ultravioletas. $\mu \mathrm{g} / \mathrm{g}$ : micrograma por grama. UVA/UVB: raios ultravioletas A/B. $\mathrm{x}$ : vezes. DNA: ácido desoxirribonucleico. $\downarrow$ : diminuído/redução. < menos. mm: milímetros. RVD: receptor de vitamina D. PNUs: polimorfismos de nucleotídeo único. 25(OH)D/25(OH)D3: 25-hidroxivitamina D. RXR: receptor-alfa de retinóide X. 1,25(OH)2D3: 1,25diidroxicolecalciferol. $\mathrm{ng} / \mathrm{mL}$ : nanograma por mililitro. $\mu \mathrm{g} / \mathrm{mL}$ : microgramas por mililitro. $\mu \mathrm{g}$ : micrograma. UI: unidades internacionais. $\mu \mathrm{l}$ : microlitro. \%: porcentagem. $\uparrow$ : elevado/aumentado. CYP24A1: 24-hidroxilase. mRNA: ácido ribonucleico mensageiro. UI/kg: unidades internacionais por quilograma. $\mathrm{x}$ : vezes. $\mathrm{mJ} / \mathrm{cm}^{2}$ : milíjoule por centímetros quadrados. $\mathrm{cm}$ : centímetro. [ ]: concentração. $\mu \mathrm{g} / \mathrm{dia}: \mathrm{micrograma}$ por dia. RNA: ácido ribonucleico. GADPH: Gliceraldeído-3-fosfato desidrogenase.

Fonte: Autores (2020).

Dentre os estudos que investigaram a influência da Vit. D sobre o CA de órgãos distintos (n=14), especificados na tabela 3, um artigo apresentou resultados de quatro experimentos diferentes (Makarova et al., 2018); Spath et al. (2017) apresentou três estudos; e Horas et al. (2019) duas experimentações. Destes, $50 \%(n=7)$ exemplificaram a relação com o CA de pele, 42,86\% (n=6) com CA de mama, e 7,14\% (n=1) com CA de pulmão.

Cabe ressaltar que em 71,43\% (n=10) dos estudos se observou a importância e influência positiva da Vit. D no processo anti-carcinogênese. Em relação aos sem resultados significativos, que representa 28,57\% (n=4), se encontram dois experimentos do CA de mama, porém, no mesmo artigo, em outros dois experimentos houveram resultados positivos (Makarova et al., 2018). Eliassen et al. (2016), não associou níveis de Vit. D como fator causal no CA de mama, mas associou a menor risco de desenvolvimento. E, no CA de pele não se estabeleceu relação segura sobre o papel da Vit. D na oncogênese 
(Park et al., 2016).

O tratamento tópico com calcitriol e exposição à raios ultravioletas (UV) foi associado com menor formação, atraso na progressão e baixo grau de malignidade tumoral (Kim et al., 2016). Alterações no gene RVD foram relacionados a sobrevida no melanoma (Orlow et al., 2016). Aqueles com melanoma demonstraram ter níveis circulantes reduzidos de 25(OH)D3, e o tratamento com 1,25(OH)2D3 demonstrou efeitos antiproliferativos, reduzindo a expressão de moléculas regulatórias do ciclo celular (Spath et al., 2017).

No CA de mama, não se relacionou a ingestão de Vit. D com o acometimento pelo CA, contudo, o tratamento com UV antes da presença do CA resultou no aumento da sobrevida global, redução no número de tumores e proliferação celular. O tratamento com Vit. D de maneira tópica não afetou a tumorigênese mamária. A partir do aloenxerto com células de CA e tratamento com UV, houve inibição do crescimento tumoral, constância que não persistiu no crescimento tumoral em ratos tratados topicamente e submetidos a aloenxerto. Os UV podem ter maior influência sobre a oncogênese de mama (Makarova et al., 2018). Para Horas et al. (2019), no CA de mama, a perda do RVD aumenta a metástase para o osso, resultando na formação de colônias tumorais, aumentando o grau do tumor e tipos de tumores mais agressivos.

Pacientes com CA de pulmão que apresentaram níveis circulantes maiores de 25(OH)D3 e 1,25(OH)2D3 foram inversamente proporcionais associados à incidência da doença, denotando a vit. D3 com importantes efeitos protetores na carcinogênese pulmonar. E, 13 PNUs associados com a vit. D se relacionaram com a carcinogênese (Haznadar et al., 2018).

A deficiência de 1,25(OH)2D3 aumenta tumores espontâneos através da proliferação celular por intermédio do estresse oxidativo e dano ao DNA, promovendo oncogênese e inibição dos genes supressores de tumor. As moléculas do fenótipo secretor associado a senescência, principalmente o fator de crescimento de hepatócitos induzidas pela deficiência de 1,25(OH)2D3, desempenham um importante papel na tumorigênese, onde o crescimento tumoral é mediado, em partes, pelo receptor c-Met. A regulação positiva de Bmi1 causada pela deficiência de 1,25(OH)2D3 desencadeia um papel crucial na aceleração do crescimento do tumor, incentivando a proliferação celular tumoral e inibindo a sua senescência mediada pela inativação das vias de sinalização p16/Rb e p19/p53, sendo este, um dos mecanismos influenciadores da oncogênese (Chen et al., 2018).

\section{Considerações Finais}

Pesquisas com diferentes metodologias, mas que tendem a evidenciar as causas contribuintes, vias de tratamento e diagnóstico são de extrema valia para a prática clínica e entendimento da exposição a fatores modificáveis para manutenção da saúde e prevenção ao câncer (CA), uma das mais agressivas e debilitantes doenças hodiernas.

Neste estudo, pode-se destacar a potencial influência da vitamina D (Vit. D) na prevenção e inibição da carcinogênese. Naqueles correlacionados ao trato gastrointestinal (TGI) e órgãos distintos, 84,62\% (n=11) e 71,43\% (n=10) dos estudos, respectivamente, evidenciaram uma correlação positiva ao processo anti-carcinogênese com níveis adequados e/ou mais elevados da Vit. D, em que, a ascendência do CA pode estar vinculada a deficiência de Vit. D, polimorfismos no gene receptor de vitamina D (RVD) e/ou demais mecanismos subjacentes. Mesmo naqueles estudos onde não se observou diferença significativa sobre a influência da Vit. D na oncogênese, se pode observar que a mesma não infere resultados prejudiciais. Portanto, os resultados destacam a influência favorável da Vit. D na prevenção da carcinogênese que acomete o TGI e órgãos distintos.

Aos estudos subsequentes, sugere-se a exploração e a ampliação da gama de substâncias utilizadas, como o uso de micronutrientes ou demais substâncias em associação ou não com a Vit. D; caracterização das vias de obtenção, utilizando e 
comparando a eficácia através dos raios ultravioletas, alimentação ou suplementação, interligando os níveis séricos do hormônio entre os diferentes tipos ou um único tipo de CA, a fim de diversificar o potencial contribuinte para a prática clínica. Além disso, evidenciar de forma concisa o impacto dos polimorfismos no gene RVD e demais mecanismos subsequentes para o influxo contribuinte. Contudo, são necessárias mais pesquisas para elucidar com segurança a contribuição da Vit. D sobre o CA, seja por via de inibição da oncogênese, tratamento, diagnóstico ou prognóstico.

\section{Referências}

Albanes, D. (2015). Vitamin D and cancer: Diversity, complexity, and still a ways to go. Cancer Prevention Research, 8(8), 657-661. 10.1158/19406207.CAPR-15-0207

Brasil. Ministério da Saúde. Instituto Nacional do Câncer José Alencar Gomes da Silva (INCA). (2020). ABC do câncer: abordagens básicas para o controle do câncer / Instituto Nacional (6a ed.). Rio de Janeiro: INCA. Recuperado de https://www.inca.gov.br/sites/ufu.sti.inca.local/files//media/document//livro-abc6-edicao-2020.pdf

Bray, F., Ferlay, J., Soerjomataram, I, Siegel, R. L., Torre, L. A., \& Jernal, A. (2018). Global cancer statistics 2018: GLOBOCAN estimates of incidence and mortality worldwide for 36 cancers in 185 countries. CA: A Cancer Journal for Clinicians, 68(6), 394-424. https://doi.org/10.3322/caac.21492

Chen, L., Yang, R., Qiao, W., Yuan, S., Goltzman, D., \& Miao, D. (2018). 1,25-Dihydroxy vitamin D prevents tumorigenesis by inhibiting oxidative stress and inducing tumor cellular senescence in mice. International Journal of Cancer, 143(2), 368-382. https://doi.org/10.1002/ijc.31317

Christakos, S., Dhawan, P., Verstuyf, A., Verlinden, L. \& Carmeliet, G. (2015). Vitamin D: Metabolism, molecular mechanism of action, and pleiotropic effects. Physiological Reviews, 96(1), 365-408. https://doi.org/10.1152/physrev.00014.2015

Deeb, K. K., Trump, D. L. \& Johnson, C. S. (2007). Vitamin D signalling pathways in cancer: Potential for anticancer therapeutics. Nature Reviews Cancer, 7(9), 684-700. https://doi.org/10.1038/nrc2196

Eliassen, A. H., Warner, E. T., Rosner, B., Collins, L. C., Beck, A. H., Quintana, L. M., Hankinson, S. E. (2016). Plasma 25-Hydroxyvitamin D and Risk of Breast Cancer in Women Followed over 20 Years. Cancer Research, 76(18), 5423-5430. https://doi.org/10.1158/0008-5472.can-16-0353

El-Sharkawy, A. \& Malki, A. (2020). Vitamin D signaling in inflammation and cancer: Molecular mechanisms and therapeutic implications. Molecules, 25(14), 1-31. https://doi.org/10.3390/molecules25143219

Eom, S. Y., Yim, D. H., Kim, D. H., Yun, H. Y.., Song, Y. J., Youn, S., \& Kim, H. (2018). Dietary vitamin D intake and vitamin D related genetic polymorphisms are not associated with gastric cancer in a hospital-based case-control study in Korea. Journal of Biomedical Research, 32(4), 257-263. https://doi.org/10.7555/JBR.32.20170089

Haznadar, M., Krausz, K. W., Margono, E., Diehl, C. M., Bowman, E. D., Manna, S. k., \& Harris, C. C. (2018). Inverse association of vitamin D3 levels with lung cancer mediated by genetic variation. Cancer Medicine, 7(6), 2764-2775. https://doi.org/10.1002/cam4.1444

Holick, M. F. (2007). Medical progress: Vitamin D deficiency. New England Journal of Medicine, 357(3), 266-281. https://doi.org/10.1056/NEJMra070553

Horas, K., Zheng, Y., Fong-Yee, C., Macfarlane, E., Manibo, J., Chen, Y., ... Seibel, M. J. (2019). Loss of the Vitamin D Receptor in Human Breast Cancer Cells Promotes Epithelial to Mesenchymal Cell Transition and Skeletal Colonization. Journal of Bone and Mineral Research, 34(9), 1721-1732. doi: https://doi.org/10.1002/jbmr.3744

Kim, J. S., Jung, M., Yoo, J., Choi, E. H., Park, B. C., Kim, M. H., \& Hong, S. P. (2016). Protective effect of topical Vitamin D3 against photocarcinogenesis in a murine model. Annals of Dermatology, 28(3), 304-313. doi: https://doi.org/10.5021/ad.2016.28.3.304

Kwak, J. H. \& Paik, J. K. (2020). Vitamin D Status and Gastric Cancer: A Cross-Sectional Study in Koreans. Nutrients, 12(7), 1-9. https://doi.org/10.3390/nu12072004

Makarova, A. M., Fracari, F., Davari, P., Gorouhi, F., Dutt, P., Wang, L., \& Epstein Jr, E. H. (2018). Ultraviolet radiation inhibits mammary carcinogenesis in an ER-negative murine model by a mechanism independent of Vitamin D3. Cancer Prevention Research, 11(7), 383-391. https://doi.org/10.1158/19406207.CAPR-17-0195

Margolis, R. N. \& Christakos, S. (2010). The nuclear receptor superfamily of steroid hormones and vitamin D gene regulation: An update. Annals of the New York Academy of Sciences, 1192, 208-214. https://doi.org/10.1111/j.1749-6632.2009.05227.x

McCullough, M. L., Zoltick, E. S., Weinstein, S. J., Fedirko, V., Wang, M., Cook, N. R., \& Smith-Warner, S. A. (2019). Circulating Vitamin D and colorectal cancer risk: An international pooling project of 17 cohorts. Journal of the National Cancer Institute, 111(2), 158-169. https://doi.org/10.1093/jnci/djy087

Messaritakis, I., Koulouridi, A., Sfakianaki, M., Vogiatzoglou, K., Gouvas, N., Athanasakis, E., \& Souglakos, J. (2020). The role of vitamin D receptor gene polymorphisms in colorectal cancer risk. Cancers, 12(6), 1-16. https://doi.org/10.3390/cancers12061379

Orlow, I., Reiner, A. S., Thomas, N. E., Roy, P., Kanetsky, P. A., Luo, L., \& Berwick, M. (2016). Vitamin D receptor polymorphisms and survival in patients with cutaneous melanoma: A population-based study. Carcinogenesis, 37(1), 30-38. https://doi.org/10.1093/carcin/bgv157 
Research, Society and Development, v. 10, n. 1, e9610111388. 2021

(CC BY 4.0) | ISSN 2525-3409 | DOI: http://dx.doi.org/10.33448/rsd-v10i1.11388

Park, S. M., Li, T., Wu, S., Li, W. Q., Qureshi, A. A., \& Cho, E. (2016). Vitamin D intake and risk of skin cancer in US women and men. PLoS ONE, 11(8), 1-14. doi: https://doi.org/10.1371/journal.pone.0160308

Pereira, A. S., Shitsuka, D. M., Pereira, F. J., \& Shitsuka, R. (Orgs.) (2018). Metodologia da pesquisa científica. Santa Maria, RS: UFSM. https://repositorio.ufsm.br/bitstream/handle/1/15824/Lic_Computacao_Metodologia-Pesquisa-Cientifica.pdf?sequence=1

Schöttker, B., Jorde, R. Peasey, A., Thorand, B., Jansen, E. H. J. M., Groot, L., \& Brenner, H. (2014). Vitamin D and mortality: Meta-analysis of individual participant data from a large consortium of cohort studies from Europe and the United States. BMJ, 348, 1-15. https://doi.org/10.1136/bmj.g3656

Spath, L., Ulivieri, A., Lavra, L., Fidanza, L., Carlesimo, M., Giubettini, \& Bartolazzi, A. (2017). Antiproliferative Effects of 1 $\alpha$-OH-vitD 3 in Malignant Melanoma: Potential Therapeutic implications. Scientific Reports, 7(1), 1-12. https://doi.org/10.1038/srep40370

Souza, M. T., Silva, M. D. D. \& Carvalho, R. D. (2010). Revisão integrativa: o que é e como fazer. Einstein, 8(1), 102-6. https://doi.org/10.1590/s167945082010 rw1134

Suksawatamnuay, S., Sriphoosanaphan, S., Aumpansub, P., Aniwan, S., Thanapirom, K., Tanasanvimon, S., \& Komolmit, P. (2020). Association between Vitamin D Receptor Single-Nucleotide Polymorphisms and Colorectal Cancer in the Thai Population: A Case-Control Study. BioMed Research International, 1-9. https://doi.org/10.1155/2020/7562958

Tian, X. Q., Chen, T. C., Matsuoka, L. Y., Wortsman, J., \& Holick, M. F. (1993). Kinetic and thermodynamic studies of the conversion of previtamin D3 to vitamin D3 in human skin. Journal of Biological Chemistry, 268(20), 14888-14892. https://www.jbc.org/content/268/20/14888.long

Verma, A., Vincent-Chong, V. K., Dejong, H., Gershberger, P. A., \& Sashadri, M. (2020). Impact of dietary vitamin D on initiation and progression of oral cancer. Journal of Steroid Biochemistry and Molecular Biology, 199, 105603. https://doi.org/10.1016/j.jsbmb.2020.105603

Vincent-Chong, V. K., DeJong, H., Attwood, K., Hershberger, P. A. \& Seshadri, M. (2019). Preclinical Prevention Trial of Calcitriol: Impact of Stage of Intervention and Duration of Treatment on Oral Carcinogenesis. Neoplasia, 21(4), 376-388. https://doi.org/10.1016/10.1016/j.neo.2019.02.002

Wacker, M. \& Holick, M. F. (2013). Sunlight and Vitamin D: A global perspective for health. Dermato-Endocrinology, 5(1), 51-108. https://doi.org/10.1016/10.4161/derm.24494

Xin, Y., He, L., Phil, M., Luan, Z., Lv, H., Yang, H., \& Qian, J. (2017). E-cadherin Mediates the Preventive Effect of Vitamin D 3 in Colitis-associated Carcinogenesis. Inflammatory Bowel Diseases, 23(9), 1535-1543. https://doi.org/10.1097/MIB.0000000000001209

Yang, L., Chen, H., Zhao, M. \& Peng, P. (2017). Prognostic value of circulating vitamin D binding protein, total, free and bioavailable 25-hydroxy vitamin D in patients with colorectal cancer. Oncotarget, 8(25), 40214-40221. https://doi.org/10.18632/oncotarget.16597

Zella, L. A., Kim, S., Shevde, N. K., \& Pike, J. W. (2006). Enhancers located within two introns of the vitamin D receptor gene mediate transcriptional autoregulation by 1,25-dihydroxyvitamin D3. Molecular Endocrinology, 20(6), 1231-1247. https://doi.org/10.1210/me.2006-0015

Zhang, Y. G., Lu, R., Wu, S., Chatterjee, I., Zhou, D., Xia, Y., \& Sun, J. (2020). Vitamin D Receptor Protects Against Dysbiosis and Tumorigenesis via the JAK/STAT Pathway in Intestine. Cellular and Molecular Gastroenterology and Hepatology, 10(4), 1-18. https://doi.org/10.1016/j.jcmgh.2020.05.010 